\title{
SPONTANEOUS PNEUMOTHORAX IN A PATIENT WITH COVID-19
}

\author{
Syeda Turab Fatima Abidi, Syed Asim Ali Shah, Aziz Ul Qadir, Huma Hussain, Rifat Yasmin, Anum Afsar, Ali Raza Hayat, \\ Rabia Asghar \\ POF Hospital Wah Cantt Pakistan
}

\begin{abstract}
The coronavirus disease 2019 (COVID-19) frequently involves the respiratory system causing pneumonia. The disease started in December 2019 and is now a global pandemic. The disease is not limited to the respiratory system and cardiac, cutaneous, and neurological involvement has been reported. Psychiatric features of agitation and delirium have also been described in COVID-19. It is yet to be determined whether this will have any long term effect on the quality of life of these patients. We report a case of delirium in a COVID-19 patient who had also developed spontaneous pneumothorax on the day 15 of illness. Few of such case reports have been reported internationally but to the best of authors' knowledge, no such case has been reported in Pakistan.
\end{abstract}

Keyword: COVID-19, Spontaneous Pneumothorax.

This is an Open Access article distributed under the terms of the Creative Commons Attribution License (http://creativecommons.org/licenses/by/4.0), which permits unrestricted use, distribution, and reproduction in any medium, provided the original work is properly cited.

\section{INTRODUCTION}

The present pandemic of coronavirus disease (COVID-19) started in Dec 2019 in Wuhan China. Since then it has spread globally. About $1-2 \%$ of patients suffer from critical illness ${ }^{1}$. COVID-19 still remains a global challenge ${ }^{2}$. It is caused by severe acute respiratory syndrome coronavirus (SARS-CoV-2) ${ }^{3}$. This virus is highly contagious and still no vaccine or effective treatment is approved, Worldwide 4 . However, World Health Organization (WHO) has reported prevention, isolation, education, transmission control and treatment of infected individuals are important steps for COVID19 Control $^{5}$. Pakistan is also affected with this disease $\left(319,848\right.$ confirmed cases till 13 Oct, 2020) ${ }^{6}$.

Pneumonia is the most common clinical condition in patients having pulmonary involvement. SARS CoV-2 can also affect gastrointestinal, cardiovascular, neurological, and other systems ${ }^{1}$. Although data is not available on psychiatric illness in COVID-19, it has been mentioned in previous Corona Virus infections ${ }^{7}$. We describe a case of a female patient with COVID-19 pneumonia, developing delirium on day 3 and spontaneous pneumothorax on day 15 of admission.

\section{CASE REPORT}

A 45-year lady presented to the emergency department with fever, cough, shortness of breath, and chest pain. She was in contact with a COVID-19 patient. On physical examination, the temperature was $38.5^{\circ} \mathrm{C}$, heart rate $110 / \mathrm{min}$, respiratory rate $25 /$ minute, and blood pressure was $150 / 100 \mathrm{mmHg}$. Saturation of

Correspondence: Dr Syed Turab Fatima Abidi, Department of Medicine, POF Hospital Wah Cantt Pakistan

Received: 13 Oct 2000; revised received: 20 Nov 2020; accepted: 23 Nov 2020 peripheral oxygen $(\mathrm{SpO} 2)$ was $87 \%$ on room air and 92\% with nasal oxygen cannula @ 5 liters. She had Diabetes Mellitus and was on Insulin. Keeping in view her clinical state and contact history, chest radiograph and HRCT were done which showed typical features of COVID-19 with CVCT 1, CORADS 5, 75\% lung involvement. Her specialized blood works including C-reactive protein (CRP), Ferritin, LDH, D-Dimers, throat, and nasopharyngeal swabs for SARS COV-2 PCR were sent. She was admitted for inpatient care. Oxygen therapy, antibiotics, Methylprednisolone, and Enoxaparin were started. Her real-time PCR for SARS $\mathrm{CoV}-2$ came positive.

On day 2 of illness, mental state changes were observed. On day 3, she became agitated, combative, and increasingly hypoxic because of non-compliance with oxygen therapy. Haloperidol and Promethazine were started after a psychiatric consultation. She had to be kept on regular doses for the next 1 week and was switched to Tab. Quetiapine orally later. Delirium resolved by day 30 of admission.

The course of COVID-19 was progressive with increasing oxygen requirements titrated by Venturi oxygen mask, a non-rebreathing mask, and finally escalated to NIPPV with a pressure support of $15 \mathrm{~cm}$, PEEP of $8 \mathrm{~cm}$ and $\mathrm{FiO}_{2}$ of 0.1 . The patient continued to improve. By day 15, requirement reduced to $35 \%$ by Venturi mask @6 liters. In the evening she suddenly deteriorated, with a respiratory rate of 30/ $\mathrm{min}, \mathrm{SpO} 2$ of $92 \%$ with NRBM @15 liters. A repeat chest radiograph was ordered and complete blood count, DDimers, Ferritin, and CRP were sent. The radiograph showed pneumothorax in the left upper lobe, with no 
evidence of surgical emphysema. A chest drain was placed.

A repeat HRCT on day 17 showed resolving pneumothorax in the left upper lobe and interval resolution of lung parenchymal changes with $25-50 \%$ lung involvement. The chest tube was removed on day 22 after the complete resolution of pneumothorax. The patient became oxygen-free by day 27 . nucleus and replicates with the release of viral particles. The ACE2 receptors are richly expressed on the apical side of the epithelial cells in the alveolar space ${ }^{3}$. The virus can likely enter and destroy them. Our case had severe lung disease at presentation. She did not have any underlying pulmonary disease, did not smoke, and had no structural abnormality predisposing her for pneumothorax. She had bouts of severe cough in the initial few days of illness but she developed

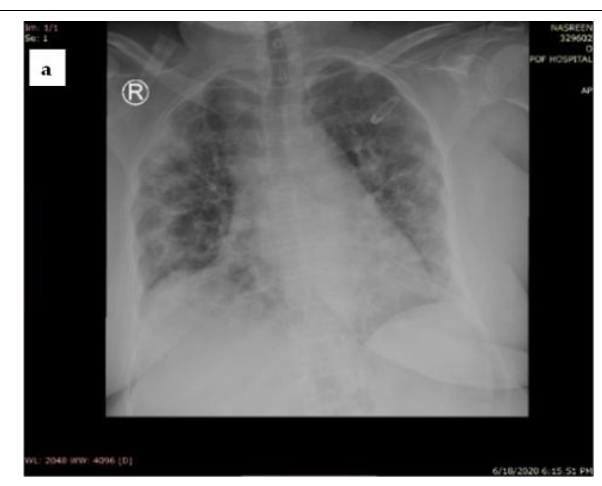

Figure-1(a): Chest radiograph showing bilateral ground glass haze more on right side.

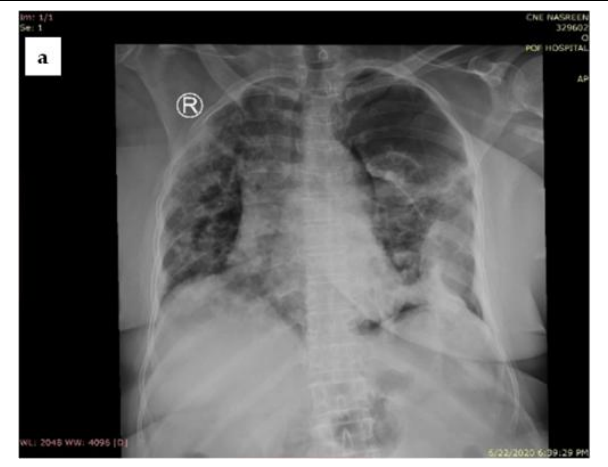

Figure-2(a): Chest radiograph showing left apical pneumothorax, with ground glass haze.

\section{DISCUSSION}

As COVID-19 spreads globally, intense research in its pathophysiology, clinical presentation, and treatment modalities continues. The disease has SARS CoV2 as its causative agent ${ }^{1}$.

Pneumonia is the most frequent clinical condition and leads to the dreaded complication of acute respiratory distress syndrome and respiratory failure. The virus gains entry into the cell by attaching to ACE2 receptors expressed in the lungs, heart, ileum, kidneys, and bladder ${ }^{8}$.

In the lungs, ACE2 receptors are expressed highly on epithelial cells. The viral RNA enters the cell spontaneous pneumothorax later in the course of illness. About $1 \%$ of COVID-19 patients have a pneumothorax. The literature has described the presence of pneumatocoeles in COVID-19 pneumonia as a result of widespread alveolar damage ${ }^{9}$. Our case developed pneumothorax in the recovery phase and did not have evidence of superimposed infection (procalcitonin 0.17 $\mathrm{ng} / \mathrm{ml}$ ). We believe that widespread alveolar damage and severe bouts of cough resulted in structural changes causing a pneumothorax. Another differential was a pulmonary embolism (PE) with D-Dimer levels of $1550 \mathrm{ng} / \mathrm{ml}$. However, as the patient was already on therapeutic anticoagulation and with new pneumotho- 
rax the probability of PE being the cause of decompensation was unlikely. A high index of suspicion for the clinical possibility of pneumothorax is needed in patients recovering from disease and deteriorating suddenly as it carries significant morbidity and mortality.

Clinical states that have been seen are headache, dizziness, altered consciousness, smell and taste disorders, strokes, seizures, encephalitis, and polyneuropathy. Critically ill patients have a higher proportion of these complications ${ }^{10}$. Encephalopathic features of agitation and delirium have also been described in COVID-19. It is also not known whether this state will prolong after the respiratory symptoms and hypoxia have settled, causing any long term cognitive deficit or quality of life impairment.

\section{CONFLICT OF INTEREST}

This study has no conflict of interest to be declared by any author.

\section{REFERENCES}

1. AU Huang C, Wang Y, Li X. Clinical features of patients infected with 2019 novel coronavirus in Wuhan, China. Lancet 2020; 395(10223): 497-502.
2. Fan $Y$, Zhao K, Shi ZL, Zhou P. Bat coronaviruses in China. Viruses 2019; 11(3): 210.

3. Wang C, Horby PW, Hayden FG. A novel coronavirus outbreak of global health concern. Lancet 2020; 395(10223): 470-73.

4. Guo YR, Cao QD, Hong ZS, Tan YY. The origin, transmission and clinical therapies on coronavirus disease 2019 (COVID-19) outbreak-an update on the status. Mil Med Res 2020; 7(1): 1-10.

5. Organization WH. WHO Director-General's opening remarks at the media briefing on COVID-19. 2020. Available from: https:// www.who.int/dg/speeches/detail/who-director-general-sopening-remarks-at-the-media-briefing-on-covid-19--11-march2020.

6. The Ministry of National Health Services Regulation and coordination. Available at: http://covid.gov.pk/stats/ pakistan

7. Rogers JP, Chesney E, Oliver D. Psychiatric and neuropsychiatric presentations associated with severe coronavirus infections: a systematic review and meta-analysis with comparison to the COVID-19 pandemic. Lancet Psychiatry 2020; 7(7): 565-66.

8. Zou X, Chen K, Zou J, Han P, Hap J, Han Z. Single-cell RNA-seq data analysis on the receptor ACE2 expression reveals the potential risk of different human organs vulnerable to 2019nCoV infection. Front Med 2020; 14(2): 185-92.

9. Ucpinar BA, Sahin C, Yanc U. Spontaneous pneumothorax and subcutaneous emphysema in COVID-19 patient: Case report. J Infect Public Health 2020; 13(6): 887-89.

10. Mao L, Jin H, Wang M, Hu Y, Chen S, He Q. Neurologic manifestations of hospitalized patients with coronavirus disease 2019 in Wuhan, China. J Am Med Assoc Neurol 2020; 77(6): 683-90. 